\title{
XXXIV. On the theory of voltaic action
}

\section{Mr. John Prideaux}

To cite this article: Mr. John Prideaux (1833) XXXIV. On the theory of voltaic action, Philosophical Magazine Series 3, 2:9, 210-220, DOI: 10.1080/14786443308648011

To link to this article: http://dx.doi.org/10.1080/14786443308648011

册 Published online: 01 Jun 2009.

Submit your article to this journal 준

LII Article views: 2

Q View related articles $₫$ 
pencil to the perpendicular about $9^{\circ}$. The angle of the cone, computed from these data, was found to be $1^{\circ} 50^{\prime}$; differing by $5^{\prime}$ only from that assigned by theory.

Examining the emergent rays with a tourmaline plate, I found that they were polarized, and according to the law already observed in the former case of conical refraction. The result was in this case predicted by theory; in the former instance it was first discovered by observation.

XXXIV. On the Theory of Voltaic Action. By Mr. Joнn PrideavX*.

Sect. I. Of the Relation between Voltaic and Common Electricity.

1. DISTINCTIONS have been drawn between electricity from the machine, and that from the voltaic apparatus; difference of tension having been considered insufficient to account for the difference of their effects. Dr. Hare is, I believe, the only chemist who has offered an explanation of this distinction, which he does by regarding voltaic as a compound of common electricity and caloric.

Because a) It warms all bodies through which it passes, unless very good and sufficient conductors, of caloric as well as of electricity.

b) A wire may be made, by a strong voltaic current, to continue radiating caloric for an indefinite time; which caloric, unless indefinitely contained in the wire, must be supplied by the current.

c) By passing through charcoal, or other bad conductors of heat, the caloric may actually be separated from the electricity, which is thus deprived of its heating power.

And hence Dr. Hare names the operation of his apparatus " calorimotion," in contradistinction to electromotion.

2. Whether Dr. Hare has abandoned this theory, I do not know. If not, it might be argued in reply,-

a) That reducing the diameter of a good conductor, disengages the heat as effectually, or even more so, than substituting a bad one.

b) That in reference to the wire, it may be made to give out light indefinitely, by heat; supplied invisibly by hot air $t_{\text {, }}$ or in any other mode, even that of the voltaic current; whence,

* Communicated by the author.

† Over a flame of hydrogen gas, as near as possible without touching it, hold a slip of platinum foil, edge downwards. The foil will continue to giow so long as it and the flame are kept steady. The little platinum spiral lanp, iu vapour of spirit, is a more striking but less unequivocal evidence ol the same thing. 
by parity of reasoning, light should be contained in both heat and the voltaic fluid, unless it also be indefinitely contained in the wire; and heat may be indefinitely continued by friction, where its source is yet more obscure.

c) That common electricity passed through a water tube is deprived of its power of deflagration, or of even affecting Mr. Harris's delicate air-electrometer*, more effectually than voltaic electricity is by passing through charcoal, which may be thus proved :-

A pair of Leyden jars, connected in both coatings, were set on an insulating stool; their outer and inner coatings communicating respectively with two balls, set at $\frac{1}{4}$ inch apart. Between the outer coating and its ball, Harris's thermotest was interposed. The prime conductor being put in communication with the inner coating, the outer having of course a communication with the ground, the machine was turned until the jars discharged themselves through the balls. The thermotest rose $12^{\circ}$, or 1.2 inch ; and so repeatedly, at the 64th turn of the machine, with a smart explosion at each discharge.

A glass tube, about 7 inches long and $\frac{5}{8}$ calibre, filled with water, and wired through a cork at each end, was now interposed between the inner coating and its ball. The discharge now took place with a sharp hissing sound, a blue spark, and no effect whatever on the thermotest, although it required 70 or more turns of the machine to make the spark pass; and very little electricity was left in the jars.

The water tube was next placed between the prime conductor and the inner coating, a similar one being made to communicate between the outer coating and the ground; - thus the jars were charged both inside and out through the water tubes; and if, in the case just quoted, the inaction on the thermotest was caused by abstraction of caloric in passing through the water, that caloric being now abstracted in charging the jars, no heat could be produced in their discharge. But on discharging them through the metallic circuit, as at first, the thermotest rose in the same manner; and on repeating and varying the experiment, the same effect was always produced by any given number of turns of the machine thrown on tive jars, whether charged through water or metal, provided they were discharged through metal; and the effect was uniformly null when the discharge took place through water.

* To avoid circumlocution or ambiguity in the frequent repetition of the words "electrometer," "galvanometer," \&c., I shalll take the liberty of distinguishing $\mathrm{Mr}$. Harris's instrument by the term "thermotest"; and the galvanometer of Professor Cumming hy the ranne " magnetest."

$$
\Leftrightarrow \mathrm{E}
$$




\section{Mr. J. Prideaux on the Theory of Voltaic Action.}

To put Dr. Hare's charcoal experiment to a test as nearly parallel as the cases seem to admit,-

A card was placed between two copper plates, bound round with wire, and set in the fire until the card was well charred. It was then taken out and put between two plates of polished copper, to each of which a wire was soldered; they were then bound round tightly with many turns of waxed thread, and a wooden wedge afterwards thrust under the thread, on each side, so as to insure the charcoal being firmly and uniformly pressed between the plates. The two wires were then made the connexion between a thermotest and a magnetest, one connected with each pole of a large voltaic pair, weakly charged. Neither instrument was distinctly affected.

A multiplier being substituted for the magnetest, the needle deviated a few degrees. A slip of bright copper was now doubled so as to pinch the plates containing the charcoal, and thus complete the metallic communication. The needle was set spinning, and the thermotest rose $10^{\circ}$ an inch.

The charge was now increased to about $\frac{1}{60}$ th of nitric acid, a smaller pair being employed (30); the charcoal and slip of copper forming the communication alternately; and the multiplier being again superseded by the magnetest. The results are given in the following table.

(The column headed "Mag." is the deflection of the needle. - "Curr." is the intensity of the current, calculated from the deflection, Becquerel's table.-Ann. de Chim. et de Phys. for August 1829. - "Ther." is the rise of the thermotest.)

\begin{tabular}{|c|c|c|c|c|c|}
\hline \multicolumn{3}{|c|}{ Through Charcoal. } & \multicolumn{3}{|c|}{ Through Copper. } \\
\hline Mag. & Curr. & Ther. & Mag & Curr. & Ther \\
\hline $25^{\circ}$ & 16 & 1.5 & $48^{\circ}$ & 60 & 8 \\
\hline 30 & 23 & 2 & 50 & 68 & 8 \\
\hline 25 & 16 & 1 & 48 & 60 & 8 \\
\hline 25 & 16 & 2 & 46 & 54 & 7 \\
\hline - & $\overline{10}$ & $\overline{2}$ & $\overline{-}$ & - & - \\
\hline Mean 27 & 18 & $1 \cdot 6$ & 48 & 61 & 8 \\
\hline
\end{tabular}

Here the electric current is obstructed by the charcoal, as well as the calorific; and the calorific effect is, in each case, in such proportion to the current as would be expected, considering that weak currents which pass through the wire without resistance do not heat it at all; whence the heat must increase at a greater rate than the current.

Thus it is seen that charcoal obstructs the electric as well as the calorific current; and that common electricity is more effectually deprived of its heating power by passing through 
Mr. J. Prideaux on the Theory of Voltaic Action. 213

water, than voltaic by passing through charcoal; and it seems to follow, that bad conductors act, in case of the shock, by diminishing its impetus; of the current by reducing its quantity; and thus allowing of their passing tranquilly through the thermotest wire.

I think I am prepared to show, on a future occasion, that the heat of electricity is proportionate to, and consequently dependent on, the resistance it encounters in the substance heated; the shock presenting some analogy with percussion, the current with friction.

Dr. Hare seems also to have regarded voltaic electricity as acting on particles, and not on masses; an opinion which has of course long yielded to the whole body of facts belonging to electro-magnetism.

3. Common electricity, produced on non-conductors, is transmitted through a greater or less thickness of air, and must therefore possess a certain degree of tension; by which, when transferred to conductors, it is forced to their surface, and retained there only by the non-conducting power of the surrounding air.

4. Voltaic electricity is produced through the medium of semi-conductors, and cannot acquire great tension, because the resistance to its return is not sufficient. But by multiplying the strata of imperfect conductors through which it must force its way to return; that is, by increasing the number of alternations, - this tension may be increased to a limit not yet ascertained.

Its production is perfectly continuous, and its quantity such, that Van Marum found his great battery charged, by instantaneous contact with 100 pair of 2-inch plates, as high as the pile itself,-a charge which would have required several turns of his gigantic machine.

And on this continual flood seem to depend the chemical and (in case of voltaism, where the impetus is small) the calorific effect; for weak piles are said by Senger to have their effects remarkably increased, in these respects, by being let off; as it were, over the large conducting surface of a coated jar; whilst by reducing the magnitude of the plates, confining their points of contact with the liquid (17), or even obstructing the conducting power of the latter, the current may be so restricted as to produce tension orly.

5. Thermo-electricity, being usually produced on perfect conductors, may be expected to be still nore free from tension than voltaic electricity; its quantity and continuity being marked by its powerful action on the needle. Yet even this may be made to affect the gold leaf electroscope; by using a metal of 


\section{Mr. J. Prideaux on the Theory of Voltaic Action.}

difficult conduction, as platinum; connecting the other end with the ground, through an imperfect conductor, as hot glass, or the finger*.

6. Though these observations leave unanswered many of the objections to the identity of voltaic and conmon electricity, those objections do not seem to me sufficient, afier the striking experiment of Dr. Wollaston + , to establish any other distinction between them than difference of tension; nor will any other distinction be considered, in the following pages, between the electrical and chemical effects of the pile. Tension is even well known to expedite and facilitate the decomposition of water and salts by the voltaic current.

\section{Sect. II. Of the received Voltaic Theories.}

7. The insufficiency of the theory adopted by the acute philosopher, whose name stands for ever enshrined in this branch of electrical science; by which the action of the pile was referred solely to the electromotive force of the metals; that is, its inadequacy to account, without noticing the decomposition of the charge, for the copious flood of electricity which distinguishes its operation,--was early perceived. And it has since been shown by experiment, varied in a multitude of ways, that decided electrical action may be produced by two pieces of the same metal, in the same fluid $(40,41,45)$; and that the efficacy of the liquid charge depends more on its facility of decomposition than on its conducting power.

8. To Dr. Wollaston is generally attributed another theory, which imputes the effects of the pile to decomposition of the liquid charge, and its chemical action on the zinc. He has been followed by Professor De la Reve, of Geneva, who goes further than Wollaston probably ever intended to do, attributing the effects entirely to the chenical action; and dis puting the validity even of Volta's leading experiment, the production of electricity by contact of zinc and copper f. But the electromotive effects of the metals are established by nume-

* Becquerel, Ann. de Chim. et de Phys. for August 1829.

+ Dr. Wollaston's experiment here alluded to, is that in which copper was deposited on the negative wire, and redissolved, by reversing the connexion. A gross analogy with voltaic decomposition may be also noticed in an experiment where the difficulty of obtaining continuity in common electricity is obviated:-

Pass a negative ball over the face of a cake of resin, in fanciful lines of any kind, and a positive ball over the same face in other lines. Dust the plate with a mixture of powdered sulphur and red lead. The powders will separate according to their electrical character, and mark out the lines described by the respective electrieities, in red and yellow.

- Aun. de Chim. et de Phys, for November 1828. 
Mr. J. Prideaux on the Theory of Voltaic Action. 215

rous and unequivocal experiments, amongst which the following may be cited as well suited to contrast it with the chemical source of electricity.

9. Professor Berzelius took 12 glasses, each 3 inches deep and $\frac{1}{2}$ inch wide, half filled them with alkalescent muriate of lime, the other half with dilute nitric acid. Into each he put a copper wire with a zinc foot, the zinc lying in the alkalescent liquid, the copper bending over into the acid of the succeeding glass. This formed what is commonly called the circle of cups.

So long as the poles were unconnected, the copper dissolved in the acid, and the zinc remained unacted on: but as scon as the connexion was made (through solution of salt), the solution of copper ceased, and the zinc began to oxidate, the zinc becoming positive (in the liquid) and the copper negative, as usual in voltaic arrangements.

Here the chemical action, which was in full play on the copper, before the electrical circulation was opened, instead of directing that circulation, was checked, and even reversed by it.

A simpler variation of this experiment will be described (14). And it will also be seen (13), that placing the zinc in an alkaline, the copper in an acid solution, is more efficacious than the contrary arrangement, although the acid acts much more freely on the zinc than on the copper.

It is also generally known, that of neutral salts, none (except sal-ammoniac) makes a more efficacious charge than sulphate of zinc, which is very unlikely to undergo decomposition.

10. Sir Humphry Davy's theory assumes that * "chemical and electrical attractions are produced by the same cause; acting in one case on particles, in the other on masses: and the same property, under different modifications, is the cause of all the phænomena exhibited by different voltaic combinations." A view so comprehensive, embracing every modification of chemical as well as electrical action, seems to include the other two, and every one that has been, or can be, attempted on the subject. But what it gains in extent it wants in distinctness.

11. It may, however, be limited by the word "attraction," and by the statements that a plate of platinum in solution of potass is positive to a plate of the same metal in acid, in consequence of the attraction of the oxygen of the acid for the one plate, and of that of the metal of the potass for the other; - a consequence not very evident. Also, that the cause of a

$$
\text { * Philosophical Transactions, 1826, Part IV. }
$$


current when two plates of zinc act in the same acid, is, one being tarnished and therefore "negative" * to the other; an explanation inconsistent with an experiment of Mr. Sturgeon's (4) , derived probably from this very paper of Davy's.

Sect. III. Of the initial Electromotion in the Metals.

12. Volta, finding that he could not exalt his electromotive power by piling pairs of zinc and copper one upon another, thought of interposing flakes of wet paper between the pairs, and succeeded. Other investigators have since varied the form of the apparatus, and every one of its elements; - have still found zinc and copper the most convenient metals for the purpose, but have made great improvement in the liquid. Nitric acid, properly diluted, seems, under all circumstances, the most efficacious of these; but for the electromotive influence only, the most effective arrangement is zinc, alkali, acid, copper.

13. With whom or when this discovery originated, I do not know; but it is stated in Berzelius, Traité de Chimie, i. 152, that the little apparatus described (9) filled, balf with alkaline, half with acid solutions, the zinc plunged in the alkali, the copper in the acid; produces more decided effects than when the zinc is placed in the acid, the copper in the alkali. In repeating this experiment I was annoyed with the negative effect of the copper stem, passing up from the zinc through the acid, from which more hydrogen was often given off than from the little copper plate which came over from the adjoining glass. This rendered the results variable; and to obviate it the plates were bent off at right angles, so as to lie flat, and shallow cups were employed instead of glasses; the depth of the strata of alkali and acid being thus reduced to $\frac{1}{4}$ or $\frac{3}{8}$ inch each, the stems had less interfering effect. The steadiness of result thus produced, suggested a simpler form of the experiment.

14. A glass tumbler being filled to the depth of $\frac{1}{2}$ inch with solution of common salt alkalised with potass + ; an inch deep of diluted muriatic acid $\ddagger$ was poured on carefully, so as to float above the alkali, without disturbing it. The latter having been coloured with logwood, the surface of separation was as distinctly visible as that of the glass was from the table.

A plate of zinc, and another of copper, each 2 inches

* The term " negative" here, and in other parts of the first section of Davy's paper, seems to be misapplied.

+ Salt $\frac{1}{2}$ ounce, water $\frac{1}{2}$ pint, liq. potass 1 ounce.

$\ddagger$ Water 1 pint, muriatic acid 3 drachms. 
square, being each furnished with a copper wire soldered on, the wires 18 inches long, and amalgamated at the further ends; these plates were alternately placed flat on the alkali, the zinc being put in the acid just above the alkaline surface, when the copper was in alkali, and vice versâ.

The following table gives the deflections of the magnetest needle.

\begin{tabular}{|c|c|c|c|c|c|c|c|}
\hline \multirow[t]{2}{*}{ 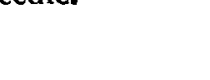 } & \multicolumn{5}{|c|}{ Experiments } & \multirow[b]{2}{*}{ Mean. } & \multirow[b]{2}{*}{ Curr. } \\
\hline & 1 & 2 & 3 & 4 & 5 & & \\
\hline Zinc in alkali & $\ldots 26^{\circ}$ & 25 & 25 & 26 & 26 & $25 \cdot 5$ & 17 \\
\hline Zinc in acid.. & $\ldots 9$ & 7 & 8 & 7 & 8 & 8 & 4 \\
\hline
\end{tabular}

The zinc was soon covered with gelatinous white oxide in the alkali; and the copper in the acid gave off hydrogen gas copiously, but without giving the slightest tinge to the liquor.

The above table gives only about the average of many experiments, some of which differed considerably from the numbers there given, influenced by the strength and depth of the alkaline solution, of which more (21).

15. If two glasses be filled with solution of common salt or sulphate of zinc, and connected by a syphon of water; and a pair of zinc and copper, connected through the multiplier, be plunged one plate in each glass, - divergence of course ensues. Now add some acid to the glass containing the zine, no increase takes place in the divergence. Change the glasses so that the copper shall be in the acidulated one, the divergence is decidedly increased.

16. In both these cases $(14,15$.) we have the zinc and copper in metallic connexion through the magnetest, and in liquid communication through the same fluids; the only difference being in the order of arrangements of the liquids.

Hence the increased effect is not attributable to varied. electrical relation between the metals; to different conducting power in the liquid, still less to chemical action, that being greatest when the zinc is in acid, where the voltaic action is least.

17. At an early period in voltaic history, Mr. De Luc analysed the pile, separating, by interposing a brass wire tripod, one of the members from each group of zinc, copper, wet cloth. His first pile was, silver, tripod, zinc, cloth; silver, tripod, \&c., and this produced all the effects of a good pile; the tripod forming a regular metallic connexion between the zinc and silver, and the wet cloth being in full communication with the other face of each.

His second pile was, silver, tripod, cloth, zinc; silver, tripod, cloth, \&c., and this produced electrical, but no cheThird Scries. Vol. 2. No. 9. March 1833. 
218 Mr. J. Prideaux on the Theory of Voltaic Action.

mical effects. The zinc and silver were in good contact, and so were the zinc and cloth; but the cloth communicated with the silver only through the points of the tripod, a contact with the liquid insufficient to convey a current capable of any chemical action.

His third pile was, zinc, tripod, cloth, silver; zinc, tripod, wet cloth, \&c.; and this produced no effects at all. The pile was inert. Yet (as noticed 16.) the communication here was the same as in the previous experiment, except that the tripod intercepted the contact of the zinc with the liquid, instead of that of the silver. But the tripod was of brass, which is negative to zinc, and was in contact with it on one side; whilst the silver, also negative, was in contact with it on the other. And De Luc attributes the inaction of this pile to the neutralizing effect of the brass and silver on opposite sides of the zinc.

18. To.see how far this explanation, which seemed very probable, would apply, the pair of plates described (14.) were connected with a multiplier; the copper placed on the table, a flake of wet paper laid on it, and the zinc plate pressed gently on the paper.

$$
\text { Deflection . . } 30^{\circ}
$$

A slip of sheet copper $\frac{1}{8}$ inch wide, and 3 long, bent into a ring 1 inch diameter, was then placed between the paper and the zinc plate (as in De Luc's third pile). The effect was (as then) null, 0, although greater pressure than before was applied on the zinc.

A slip of sheet zinc, of similar dimensions to the copper, and similarly bent, was now substituted for it.

Deflection . . $27^{\circ}$

The paper was now taken up from the copper, and the zinc ring laid on the copper plate; then wet paper, then the zinc plate.

Deflection . . . $0^{\circ}$

The zinc ring was now removed, and the copper one substituted for it, between the paper and the copper plate.

\section{Deflection . . $15^{\circ}$}

So that interception of the contact between either of the metals and the liquid, by a ring of the electro-opposite metal, entirely intercepts the current.

19. The action when the wet paper was in full contact with the copper, and only with the ring of zinc, gave deflection $27^{\circ}$.

When in entire contact with the zinc plate, but only with the ring of copper,

$$
\text { Deflection . . } 15^{\circ}
$$

15 to $27^{\circ}$ deflection being in the proportion of 8 to 19 of electrical current. And this held good (not as to exact pro- 
portions,) whether water, a saline solution, or an acid was employed.

But on soaking the paper in a strong alkaline solution (liquor potassæ), the rate was inverted, and the maxinum effect produced when the liquid was in full contact with the zinc.

Alcohol produced, as might be expected, no effect whatever.

In these experiments, the effect of the copper is weakened by the liquid in contact with it being electro-positive (alkaline), and destroyed by the interposition of a ring of positive metal. (zinc) between it and the liquid. And the effect of the rinc is reduced by negative character in the liquid with which it is in contact, or annulled by the interposition of a ring of negative metal between it and the liquid.

20. This similar effect of homo-electric metals and liquids, and vice vers $\hat{a}$, in their contact with the voltaic plates, seems to offer a clue to the theory of the cases, $(9,13,14,15,45$, and of other unexplained phænomena of the pile. If a negative metal, placed between the zinc and the liquid, neutralizes the effect of the silver on the other side, has not a negative property in the liquid itself a similar tendency?-modified and impaired, of course, by the mobility and unsteadiness of liquid particles.

If it be so, when a negative liquid is in contact with the zinc of a voltaic pair, the effect should be (except chemical action, 40.) the difference between the influence of the negative metal and the negative liquid. On the other hand, when the negative liquid is in contact with the copper, the effect should be, the influence of the zinc, plus that of the negative liquid. And if we possessed a liquid of good conducting power, which should be electro-positive to zinc, the condition of that metal might be likewise exalted. But here we are restrained by the non-conducting power of oils, naphtha, alcohol and the like; and as water is negative to zinc, and alkaline solutions seem to lose in conducting power faster than they gain in electro-positive condition, a solution of neutral salt slightly alkalized seems to answer the best purpose with this metal: for-

21. In experiment (14.) when the alkaline liquid contained a double quantity of potass, and was poured in nearly an inch deep, the effect was remarkably weakened, the deflection of the needle not exceeding $10^{\circ}$ or $12^{\circ}$; and very little oxide formed on the zinc, or hydrogen on the copper. But-

22. When the liquid was of the strength given $(14$, note) and only $\frac{1}{2}$ inch deep, - as the zinc became coated with gelatinous white oxide, so the alkaline stratum was gradually becoming shallower, by the electrical current carrying it up into the acid; and thus what was lost in conducting power by the 
coating of oxide, was gained, on the other hand, by the reduction of the alkaline stratum; and the consequence was a singular steadiness of action, the needle continuing for an hour within a degree or two of its maximum deflection.

This durability of action offers the means of a new class of voltaic researches, on which I am not yet prepared to make any report.

23. From multiplied experiments of the kind above quoted, il may be inferred that the metals partake of the electrical character of the liquids in contact with them; their electric condition being exalted if that liquid is similar, and depressed if it is of the opposite kind. And hence the fact observed by Morichini, that an addition to the quantity of copper increases the power of a voltaic pair, the charge being always negative, and therefore homo-electric with copper.

24. Whatever be the nature of electricity, it would seem to be comected with material particles by something analogous to affinity; inducing bodies which are naturally positive, to withdraw positive electricity from those which are naturally negative, when brought into mutual contact. In what way they do this I am unable to conceive in a manner consistent at once with the phænomena, with chemical analogy, and with probability; nor are experimental indications very easily found. I may perhaps venture the surmise, that repulsion is the stimulative, attraction the suppressive, principle of voltaic agency.

[To be continued.]

XXXV. Further Demonstration of the Existence of a real or imaginary Root for any proposed Equation. By R. Murphy, Esq., M.A., Fellow of Caius College, Cambridge.

To the Editors of the Philosophical Magazine and Journal.

Gentlemen,

IN your Number for January, you favoured me with the insertion of a simple demonstration relative to the existence of a real or imaginary root for any proposed equation. I beg leave to reproduce that proof in a more distinct point of view in the present Number.

When the equation $f(x)=0$ is of odd dimensions, it is known from the simplest principles that there exists a real root.

When the function $f(x)$ is of even dimensions, put $p+q \sqrt{-1}$ for $x$; where $p$ and $q$ are real quantities, the result $R$ will evidently be of the form $P+Q \sqrt{-1}$. Where 